\title{
JCAPS
}

\section{TRANSLATING PROFESSIONAL DEVELOPMENT FOR CAMPUS ACTIVITIES INTO HIGHER EDUCATION SCHOLARSHIP}

\author{
Danielle DeSawal, Indiana University - Bloomington \\ Adam Peck, Illinois State University \\ Steven McCullar, St. Cloud State University \\ David M. Rosch, University of Illinois at Urbana-Champaign \\ Stephanie Russell Krebs, University of Tampa
}

Professional development provides an opportunity to expand individual knowledge, network with colleagues, and share stories about how our students experience higher education. Magolda and Carnaghi (2017) point out that professional development needs to "recognize the value of knowing and acting" to link the learning an individual professional engages in with the students that they serve (p. 537). Komives (1998) described a "practitioner-scholar" (p. 179) as an individual who is both involved in the applied work of the profession and understands the research and literature that informs professional practice. Involvement in professional development can be the first step to identifying a topical area that would contribute to the advancement of professional practice if translated to a scholarly article. Student affairs has many documents that guide thinking about what specific knowledge is needed to work in higher education settings (e.g., Professional Competency Areas for Student Affairs Educators). Most professional associations provide blueprints for how knowledge acquisition can be shared with colleagues looking to gain similar skills and outcomes (e.g., conferences, webinars, mentoring programs, etc.). The engagement of professionals within professional development environments offers the opportunity to share stories about how our work impacts those we serve on campus and enhances how we understand the function of our roles as administrators and educators.

The Journal of Campus Activities Practice and Scholarship offers campus activities professionals a space to embrace the idea of being a practitioner-scholar. The remainder of this article provides a framework for how campus activities professionals can translate professional development events and activities into a scholarly article. We begin with the current state and importance of professional development in student affairs. That is followed by a framework for how to consider translating a professional development event or experience into a format that contributes to the scholarship of campus activities. We conclude with how the types of professional development opportunities available can contribute to the development of a scholarly article.

\section{MOVING PROFESSIONAL DEVELOPMENT ONLINE}

Engagement in professional development events and activities has always been critical to establishing opportunities in campus activities to connect with others, share stories in a community of practice, and learn strategies for how to respond to contemporary issues. Conversing with colleagues has been a standard method of sharing how we do our work and what might be frustrating us about our work environments. Professional association meetings, such as NACA Live and NACA's fall regional conferences, have long been designed to provide community support, a place to discuss issues, an outlet for sharing best practices, a means to integrate cutting-edge scholarship with day-to-day practice, and an opportunity to personally connect with friends and colleagues. 
These events and activities play a significant role in highlighting issues/topics that can be translated into a scholarly article to expand the scholarship focused on campus activities.

The rapid closure of college campuses in March 2020 also included the cancelation of many in-person professional conferences that extended through the entire 2020-2021 academic year. Professional associations play a crucial role in connecting student affairs professionals who share common roles on college campuses. Our professional associations have responded by building a virtual presence where professionals can engage at various levels. These resources became available at a price-point and an open-access level that we have not seen in higher education in quite some time. NACA Virtual, for example, in October 2020 featured over 40 educational sessions, 75 showcasing acts, and headliner keynote speakers like Dr. Marc Lamont Hill, host of HuffPost Live and BET News. While these professional development opportunities have moved online, they continue. Additionally, the online platforms have increased the access professionals have to participate in these events and activities.

Professional associations have also responded to the pandemic's known budgetary impact on various student affairs offices by using these technologies to provide free or low-cost spaces in innovative ways. For example, numerous open-access webinars have been created to address current issues in real time. NACA hosted a "Coffee \& Conversation: Healthy Dialogue-Speaking Up and Calling In" on Election Day 2020 that offered a space to engage in healthy dialogue during a tense time. Online discussion boards have also provided the opportunity for professionals to share policies and procedures, as well as ask for resources to help support their students and staff navigate current issues. Reduced-cost attendance for online conferences and open access materials has demonstrated the commitment professional associations make in providing developmental opportunities focused on knowledge acquisition, disseminating materials, networking with colleagues, and interactive spaces to share our individual stories.

While much may have changed during 2020 with regard to how the profession operates day-to-day, the skills necessary for success in student affairs and campus activities have not. The Professional Competency Areas for Student Affairs Educators (ACPA/NASPA, 2015) identifies ten professional competency areas, each with a set of knowledge, skill, and dispositional outcomes that span foundational, intermediate, and advanced proficiency. These competencies are designed to provide a broad criterion intended for all student affairs educators, regardless of their specific functional area. Individual professional associations have also established competencies for their specific functional area (e.g., NACA, ACUHO-I, and ACUI). NACA developed the Competencies for Campus Activities Professionals (2018) and the NACA Competencies for Diversity and Inclusion (2018). In both documents, it is noted that the competencies are designed to be used in collaboration with the Professional Competency Areas for Student Affairs Educators (ACPA/NASPA, 2015) to address the typical work of campus activities professionals. These documents provide a shared language and highlight the areas of knowledge campus activities need to be successful.

\section{FRAMING PROFESSIONAL DEVELOPMENT EXPERIENCES FOR PUBLICATION}

Defining professional development has been an arduous task for the field. Winston and Creamer (1998) defined the term as "an event or activity performed outside or beyond daily work duties and activities" (p. 29). Scholars also consider those activities or events to be part of a career-long process that benefits the individual and the organization in which they work (Carpenter \& Stimpson, 2007; Woodward \& Komives, 1990). Models of professional development within the field offer a framework to think about how to approach engagement, what to expect from that engagement, and why it is important to individual growth and development. Some may wonder why it is necessary to translate a professional development experience into a scholarly article. The dissemination of scholarship contributes to the growth of the profession and communicates clearly how literature and research inform professional practice. NACA members reference the significance of involvement in the organization to gain insight into other institutions' practices. Providing a venue to translate those practices into scholarly articles is why the Journal of Campus Activities Practice and Scholarship was established. We will use the PREPARE Model of Professional Development (Komives \& Carpenter, 2016) as a framework for how to embrace the idea of being a scholar-practitioner and translate a professional development experience into a scholarly article. 
Using the acronym "PREPARE," Komives and Carpenter (2016) introduced considerations for what professional development "should be" (p. 421) from a contemporary lens. These professional development considerations are presented below with a lens of developing a scholarly article.

Purposeful, intentional, and goal-related. Consider how you select the programs and events you will attend. Often the title of an event or activity is what attracts us to an event. As a prospective author, consider what resonates with you during and after the experience. NACA developed the Competencies for Campus Activities Professionals (2018) and the NACA Competencies for Diversity and Inclusion (2018). These competencies provide a blueprint to identify areas of interest for student activities professional's development. Using the competencies to identify a specific focus will set up any prospective author for an intentional and purposeful article grounded in a shared language among campus activities professionals.

Research, theory, and data-based. Practices need to be grounded in research, theory, and data. Often during a professional development event or activity, we focus more on discussing the logistics of a practice and gloss over the research and literature that framed the development of the practice. Once a prospective author has identified a specific focus, they will need to gather salient citations to support the actual practice being discussed. This will require the author to create a written review of the literature to frame the topic being discussed.

Experience-based. Professionals are encouraged to "learn from more experienced ones" (Komives \& Carpenter, 2016, p. 422). A scholarly article should acknowledge the most current discussion about a given topic. Prospective authors need to consider the audience for the article. JCAPS is focused on advancing the scholarship focused on campus activities. While the initial audience will be practitioners within campus activities, it is important to consider that scholarly pieces can be key in supporting the initiation/advancement of a policy/practice (e.g., interdisciplinary leadership program, diversity requirement initiatives, etc.).

Peer-reviewed. Komives and Carpenter (2016) note that peer review is "an underutilized resource" (p. 422). Prospective authors should share their work with peers prior to submission to gather initial feedback. Being willing to be vulnerable and share your work will improve the narrative you create within the article. Prospective authors should identify a couple of peers who would be willing to review a draft of the article and offer feedback.

Assessed. After gathering feedback from peers, the authors should assess the article to determine what areas need improvement.

Reflected on and reflected in practice. Translating a professional development event or activity to a scholarly article takes time. At this point, it is time to submit the article for review. Authors should reflect on the process they undertook to write the article and how it will contribute to the campus activities profession.

Evaluated. The blind review's formal process is where the author will see an evaluation of their work from peers. The most difficult part of the process is that it is not guaranteed that your piece will get published at this stage. What is guaranteed is that you will receive constructive feedback to improve your article for resubmission.

Participation in professional development events and activities are the foundation of how we learn what works and does not work on our college campuses. Those experiences are often privileged to individuals that can attend those meetings. Translating those topics into a scholarly article increases access to the information and intentionally frames the topic to be transferable to multiple campus environments. The next piece to consider is where to look for professional development events and activities.

\section{PROFESSIONAL DEVELOPMENT OPPORTUNITIES}

In the best of circumstances, there are many impediments to prioritizing one's professional development in higher education, which has long existed within a deep and sustained cycle of change. While times of change demand new skills and abilities, responding proactively requires forethought, patience, and sustained effort. Coupled with an institutional tendency for staff to pile new responsibilities on top of old ones, it can seem like 
the workload within campus activities grows increasingly more unsustainable each year. Staff expertise can be considered the most important strength in a university community (Blackmore \& Blackmore, 2006). While it can be tempting to digest professional development experiences for individual gain, a significant corollary goal should be to bring new knowledge, skills, and expertise back to your home institution to improve the intellectual capital of others that did have the opportunity to attend. Further, sharing that information in a scholarly article is a way to intentionally advance the campus activities profession.

We must be specific about the outcomes that we want to achieve. In a recent edition of Campus Activities Programming, Bowhay and Collier (2020) wrote, "Successful individuals are systematic in setting and achieving their career goals. Simply committing your plan to paper can improve your chance of realizing it" (p. 7). With time and money both in short supply, what activities provide the greatest "bang for our buck?" In the sections below, we discuss how the types of professional development opportunities available can contribute to developing a scholarly article.

\section{National/Regional Conferences}

National and regional conferences provide a space to gather with a large constituency of individuals who share similar roles and responsibilities. At the national level, the events and activities offered highlight contemporary issues facing the field and attract participants from all levels (e.g., mid-level, senior, etc.). This is an ideal space to begin to note topical areas that may be represented in presentations but may be missing from the scholarship of campus activities. Regional conferences offer geographically bound events and activities. Many higher education professionals are geographically bound when searching for opportunities to advance in their careers. For this reason, the relationships they can form at these conferences may benefit them in different ways than in participating at national conferences, which are often larger and offer less time for personal connections. The smaller, more personal connections could provide the opportunity for a prospective author to find other professionals to co-author a scholarly article.

\section{Online Discussion Boards and Communities}

Online discussion boards and communities are often free and offer many of the same advantages of attending a conference. Whether someone is bold enough to pose a question to the group or simply enjoys "lurking and learning" from others, there are groups on a wide variety of topics.

Many professional associations host their own communities that can focus on specific role responsibilities, individual shared identities, or contemporary issues impacting the field. These are often a benefit of professional membership and do not carry an additional cost. For example, NACA offers "NACA Connect," an online listserv platform available to all members that allow them to select from a wide variety of communities and topics. These venues also offer an opportunity to present an idea for a scholarly article to gather some initial interest in the topic. Simply asking if an article on " $\mathrm{X}$ " would be useful to the community can initiate a conversation that may help frame a prospective author's focus.

\section{Webinars/Online Courses/Credentials}

Structured online educational resources offered by institutions, third-party organizations, and associations provide another method for learning. One good way to evaluate these opportunities is to look at the promised learning outcomes. Are they specific or general? Do they seem attainable in the time frame allowed? Are they skills and abilities that the learner hopes to acquire? The more the stated goals seem realistic and aligned with your own specific development plan, the more likely the experience will be beneficial.

One-time programs possess value, and many associations and trainers are beginning to stack repeated experiences to offer new credentials and even certifications. Massive Online Open Courses (MOOCs) have become very popular. Organizations like Coursera offer many of these for free, while there may be additional costs for individuals who want to receive a credential. In addition, these courses are often designed with busy adult learners in mind, so they are created to be consumed in small chunks. This can allow the active campus activities pro- 
fessional to add them to their calendar at their own pace to gain new knowledge and skills. These opportunities can also be a source for salient references to include in an article.

\section{NACA Encore}

NACA offers a web-based resource called "Encore" which is a veritable treasure trove of resources, including past issues of NACA's Campus Activities Programming magazine, conference presentations, and more that are searchable by topic or date. Whether professionals are conducting research for a conference presentation or publication, or looking to learn more about a topic of interest, this resource is included as part of a NACA membership.

\section{Podcasts}

The vast majority of podcasts are free to consume. While the focus and content of podcasts overall are as diverse as most other products offered online, several high-quality podcasts are dedicated to topics relevant to higher education and student affairs. For example, "The Student Affairs Spectacular" (available through The Student Affairs Collective), released episodes relevant to student affairs professionals, examining issues such as race, game theory, pursuing a doctorate, and supervision in student affairs. Re:Learning Podcast is hosted by The Chronicle of Higher Education and focuses on broad issues relevant to the higher education environment. Some podcasts focus on specific issues that directly relate to the work of campus activities. For example, The Leadership Educator, hosted by Dan Jenkins and Lauren Bullock, covers university student leadership development topics. Podcasts can be consumed while cooking in the kitchen, exercising, or relaxing during a break. As we mentioned, they are available anywhere the internet can be accessed through sites like Apple, Spotify, and Stitcher. Podcasts offer another venue for gathering topical ideas for a future article.

\section{Communities of Practice (CoP)}

A CoP is often simply defined as a group of people who "share a concern or a passion for something they do and learn how to do it better as they interact regularly" (Wenger, 2011, p.1). The rapid rise of web-based communications technology allows campus activities professionals to build and engage in communities focused on campus activities practice from wherever they are. Professionals might create a recurring time for their professional colleagues to come together during a videoconference to discuss relevant issues of interest - such as how to engage students virtually, creating online programming opportunities, or partnering with other campus units to improve the student experience. These communities can be created at any point and with as little front-end investment as a group email and a Doodle poll. Using CoP's could help generate a series of articles about a topic that would be beneficial to advancing the scholarship of campus activities. The CoP can also be designed to serve as a writing group.

\section{CREATING SCHOLARSHIP AS PROFESSIONAL DEVELOPMENT}

As discussed earlier, a practitioner-scholar actively reads the research and scholarship in the field. Reading research can expose us to new theories, guide our practice, and offer new frameworks for creating student learning or methods for assessing it. A central goal of JCAPS is creating and sustaining a culture of scholarship in the campus activities field. As this editorial board has previously stated, in a time of scarce resources and rapid change, the ability to demonstrate our effectiveness - not just on our own campuses, but for the field as a whole will be essential. (Peck, McCullar, Rosch, DeSawal, Krebs, 2020). Conducting research and presenting scholarship can help practitioners to be better consumers of research in general. Booth, Colomb, and Williams (2016) wrote, "learning to do research... will help you understand what you read as nothing else will. You can accurately judge the research of others only after you've done your own and can understand the messy reality behind what is so smoothly and confidently presented in textbooks or by experts on TV" (p. 3). Professional development events and activities offer a platform for the presentation of research-based scholarship, and those events provide the opportunity to identify a phenomenon that could be researched.

Yet, many within the field may be hesitant to approach conducting research themselves. When considering the purpose of research, the focus is often on disseminating knowledge to advance the profession. But there is a second, less often cited purpose of research - to teach ourselves. Booth, Colomb, and Williams (2016) wrote, “.... a research 
topic is an interest stated specifically enough for you to imagine becoming a local expert on it. That doesn't mean you already know a lot about it or that you'll have to know more about it than others" (p. 34). Put simply, publishing research is not exclusively a demonstration of knowledge; it is part of the process of acquiring knowledge ourselves.

\section{CONCLUSION}

Professional associations continue to serve a critical role in providing the field with a blueprint for how knowledge acquisition can be shared with colleagues looking to gain similar skills and outcomes. As we discussed, NACA developed the Competencies for Campus Activities Professionals (2018) and the NACA Competencies for Diversity and Inclusion (2018). These competencies provide a blueprint to identify areas in which you want to grow as a professional and where we need to focus our scholarship related to campus activities. Using the PREPARE model of professional development to help think about how to translate an article to professional development opportunities, we outlined how a prospective author can consider translating a professional development event or activity to a scholarly article.

The editorial board of JCAPS is committed to helping scholars develop in the field of campus activities. We believe that engagement in professional development events and activities is at the foundation for understanding the information that needs to be disseminated widely to advance the campus activities profession. As such, we are willing to commit our time to individuals who submit to this journal. Academic journals are ranked based on how often the articles they contain are cited in subsequent research. Our central goal is to help professionals translate salient practices into accessible work that benefits the advancement of campus activities. To that end, we are more than willing to support authors through the publication process in translating events and activities into a scholarly work.

Lastly, our professional associations, especially NACA for campus activities professionals, have invested in their members to continue to deliver content at a reduced cost as institutions navigated change in their institutional operations. Our job as professionals is to contribute to and increase the access regarding how campus activities contribute to reimaging student engagement and learning on campus for professional growth.

\section{REFERENCES}

ACPA-College Student Educators International \& NASPA-Student Affairs Administrators in Higher Education. (2015). Professional competency areas for student affairs educators. https://www.naspa.org/images/uploads/main/ACPA_NASPA_Professional_Competencies_FINAL.pdf

Blackmore, P., \& Blackwell, R. (2006). Strategic leadership in academic development. Studies in Higher Education, 31(03), 373-387.

Booth, W. C., Colomb, G. G., Williams, J. M., Bizup, J., \& FitzGerald, W. T. (2016). The craft of research. Chicago: The University of Chicago Press.

Bowhay, V., \& Collier, I. (2020). 8 steps to develop a successful and fulfilling career plan. Campus Activities Programming, 56(6), 6-7.

Carpenter, D. S., \& Stimpson, M. (2007). Professionalism, scholarly practice, and professional development in student affairs. NASPA Journal, 44(2), 265-284.

Komives, S. R. (1998). Linking student affairs preparation with practice. In N. J. Evans \& C. E. Phelps Tobin (Eds.), The state of the art of preparation and practice in student affairs. (pp. 177-200). American College Personnel Association.

Komives, S., \& Carpenter, S. (2016). Professional development as life-long learning. In G. McClellan \& J. Stringer (Eds.), The handbook for student affairs (4th ed., pp. 411-430). Jossey-Bass.

Leadership Educator Podcast. Jenkins, D. and Bullock, L. https://theleadershipeducator.podbean.com/.

Magolda, P., \& Carnaghi, J.E. (2017). Evolving roles and competencies: Professional development reconsidered. In J.H. Schuh, S.J. Jones \& V. Torres (Eds.) Student Services: A handbook for the profession (pp. 532-549). John Wiley \& Sons. 
NACA-National Association for Campus Activities (2018). Competencies for Campus Activities Professionals. https://www.naca.org/Resources/Pages/CampusActivitiesProfessionals.aspx

NACA-National Association for Campus Activities (2018). Competencies for Diversity and Inclusion. https:// www.naca.org/Resources/Documents/Competencies_for_Diversity_and_Inclusion.pdf

Peck, A., McCullar, S., Rosch, D.M., DeSawal, D., \& Krebbs, S.R. (2020). Lessons from a Pandemic: The Value of Campus Activities Professionals. Journal of Campus Activities Scholarship and Practice, National Association for Campus Activities, 2 (2).

Price, S. D. (2005). 1001 smartest things ever said. Guilford, CT: Lyons Press.

Re:Learning Podcast. The Chronicle of Higher Education. https://www.chronicle.com/package/re-learning-podcast/.

The Student Affairs Spectacular. The Student Affairs Collective. https://www.studentaffairscollective.org/student-affairs-podcast/.

Winston, R. B., Jr., \& Creamer, D. G. (1998). Staff supervision and professional development: An integrated approach. In W. A. Bryan \& R. A. Schwartz (Eds.), Strategies for staff development: Personal and professional education in the 21st century. (New Directions for Student Services No. 84, pp. 29-42). Jossey-Bass.

Woodard, D. B., Jr., \& Komives, S. R. (1990). Ensuring staff competence. In M. J. Barr \& M. L. Upcraft (Eds.), New futures for student affairs (pp. 217-238). Jossey- Bass.

Wenger, E. (2011). Communities of practice: A brief introduction. University of Oregon Scholar's Bank. 